Artigos

\title{
Reflexões teóricas sobre a aula de língua estrangeira: organizando materiais, analisando contextos, definindo percursos
}

Theoretical reflections on foreign language lessons: organizing materials, analyzing contexts and defining paths

\author{
Cibele Cecilio de Faria Rozenfeld ${ }^{1}$ \\ Nelson Viana ${ }^{2}$
}

RESUMO

O planejamento de aulas de línguas estrangeiras constitui processo complexo, que merece atenção especial do professor, por exigir importantes reflexões de natureza teórica em relação a elementos subjacentes e a decisões sobre ações pedagógicas. Neste trabalho, abordamos tais elementos e apresentamos uma proposta de representação da constituição da aula. Para tanto, nos apoiamos teoricamente em autores que versam sobre planejamento de cursos (Barbirato e Silva, 2018), de aulas (Rozenfeld e Viana, 2006 e Almeida Filho, 1993/2008; 2012), sobre Letramento Crítico (Cope; Kalantzis, 2000) e Multiletramentos (Rojo e Moura, 2012). Assim, o objetivo deste trabalho é apresentar reflexões

1. Professora assistente doutora no Departamento de Letras Modernas da Faculdade de Ciências e Letras da Unesp. Araraquara, São Paulo - Brasil. https://orcid.org/0000-00018915-9541. E-mail: cibeleroz@gmail.com.

2. Professor associado do Departamento de Letras da Universidade Federal de São Carlos. São Paulo - Brasil. http://orcid.org/0000-0001-9712-6432. E-mail: nlsviana@gmail. com 


\section{ABSTRACT}

Foreign language lesson planning is a complex process that requires special attention from educators due to the important theoretical reflections related to both pedagogical decisions and the constituent elements of a classroom. In this article we analyze this process and propose a new theoretical framework to guide foreign language lesson planning. Our considerations are theoretically grounded on authors who discuss foreign language course planning (Barbirato \& Silva, 2018), foreign language lesson planning (Rozenfeld e Viana, 2006 e Almeida Filho, 1993/2008; 2012), Critical Literacy (Cope; Kalantzis, 2000), and Multiliteracies (Rojo e Mouro, 2012). The main goal of this paper is to develop theoretical considerations about the essential concepts in foreign language teaching and to propose a theoretically oriented lesson structure, seeking to better inform the reflective teaching practices of language educators.

Keywords: foreign language teaching; lesson planning; multiliteracies, critical literacy.

\section{Introdução}

A aula de língua estrangeira (doravante LE), sob perspectiva contemporânea, constitui espaço rico de reflexão sobre língua, cultura(s), ética, valores, diversidade, atualidades e, no processo de ensino-aprendizagem, ela está imbuída, implícita ou explicitamente, de determinada concepção acerca de tal processo (Candau, 2013). Segundo a mesma autora, todo processo de ensino-aprendizagem é "situado", o que significa, de acordo com sua exposição, que "a dimensão político-social lhe é inerente, pois acontece sempre em uma cultura específica" (ibidem, 2013:15). Essa dimensão é de grande relevância, na medida em que permeará todo o processo de ensino-aprendizagem. 
No percurso da história do ensino de línguas estrangeiras, as formas de se olhar para esse processo e concretizá-lo nas aulas de línguas foram teorizadas de formas diferentes, em especial, a partir das noções de abordagens, métodos e técnicas. Esses conceitos já foram amplamente discutidos em trabalhos científicos da área, pois são fundamentais para se compreender a prática de sala de aula. Em nossa percepção o processo de planejamento de aulas está diretamente relacionado aos conceitos abordagem, método e técnica.

Assim, neste trabalho, visamos refletir sobre o processo de ensinar uma língua estrangeira e propor princípios de planejamento de aulas que possibilitem ao professor organizar seu fazer pedagógico considerando todos os elementos da complexa teia de elementos inerente a tal processo. Visamos, assim, contribuir para melhor organização estrutural da aula, em especial por parte daqueles profissionais que estão no início de sua experiência/prática docente.

Em relação à organização deste artigo, apresentamos, na seção 2, o arcabouço teórico, na 3 uma proposta de representação das fases da aula e, por fim, tecemos as reflexões finais.

\section{Aporte teórico sobre o planejamento e as aulas de LE}

Para discutirmos o planejamento e as aulas de línguas, é necessário voltarmos às noções de abordagem, método e técnica, a fim de termos o respaldo teórico necessário para as reflexões. Vale destacar, porém, que nos referimos, neste trabalho, às aulas de cursos presenciais, considerando que coexistem, na contemporaneidade, também outros formatos de ensino, como a modalidade a distância e a híbrida (modalidade que combina ensino presencial com ensino a distância).

Assim, discutiremos na primeira subseção (2.1) os conceitos de abordagem, método e técnica; na seguinte (2.2) focalizaremos trabalhos já realizados com foco em planejamento, para então, na seção 3 , apresentarmos uma proposta de representação da aula presencial de língua estrangeira. 


\subsection{Revisitando as noções de abordagem, método e técnica}

Para entender o planejamento de aulas, é importante ter em mente os conceitos de abordagem, método e técnica, tendo em vista o uso, muitas vezes equivocado, que é feito dos termos.

Almeida Filho (2012), baseado em Anthony (1963), define abordagem como a visão sobre o processo de ensinar e aprender que modula o professor e converte conhecimentos (explícitos ou implícitos) em ação de ensino da nova língua. Essa ação representa "a materialização de uma força potencial que pode mover os agentes (professores, alunos e terceiros) para atuar no ensino e na aprendizagem" de uma língua. (ibidem, 2012:13). Em outras palavras, a abordagem relaciona-se ao conjunto de crenças, pressupostos teóricos, ideias, valores, conhecimentos de mundo, de língua e de sala de aula do professor, que lhe permitirá delinear suas ações didático-pedagógicas.

Em uma escala hierárquica, a partir dessa visão e dos pressupostos da abordagem, delineia-se a noção de método. De acordo com Almeida Filho (2012:70), método já seria algo mais concreto e "ele é importante por materializar/viabilizar uma experiência de aprender a língua-alvo". Para o autor, o método "é o meio constituído da produção de experiências na e até certo ponto sobre a língua-alvo" e dá origem a um conjunto de ações ou atividades que consideramos necessário para levar a aprender uma língua estrangeira. Portanto, o método é a "realidade processual", que reúne as premissas do professor (abordagem) materializadas em ações docentes. Em consonância com tal definição, Leffa (1988) defende que

o método tem uma abrangência mais restrita e pode estar contido dentro de uma abordagem. Não trata dos pressupostos teóricos da aprendizagem de línguas, mas de normas de aplicação desses pressupostos. O método, por exemplo, pode envolver regras para a seleção, ordenação e apresentação dos itens linguísticos, bem como normas de avaliação para a elaboração de um determinado curso. (Leffa, 1988: 212)

É importante salientar que o método pode envolver, ainda, as extensões da sala de aula, ou seja, as ações discentes que ocorrem fora do espaço institucional. 
Vilaça, por sua vez, parte da etimologia da palavra: método vem do grego métodos e denota sucessão, ordenação. Nessa perspectiva, o autor define o conceito como "relacionado a um caminho que, seguido de forma ordenada, visa chegar a certos objetivos, fins, resultados, conceitos etc.” (VILAÇA. 2008: 75).

Um método inclui diferentes técnicas, definidas como procedimentos "que preenchem as atividades ou unidades" que formam a aula. (Almeida Filho, 1993/2008, p.73). Larsen Freeman e Anderson (2011) também defendem que o conjunto de princípios associados às técnicas e aos procedimentos constitui o método, que é "consistente com uma abordagem $^{3}$. (Larsen-Freeman e Anderson, 2011, s/p). De acordo com os autores, o conhecimento de diferentes métodos auxilia o professor a ampliar seu repertório de técnicas.

No sentido de Anthony (1963), Leffa (1988) e Almeida Filho (2012), os conceitos abordagem, método e técnica podem ser representados, portanto, conforme propomos na Figura 1.

Figura 1 - Representação da inter-relação entre os conceitos

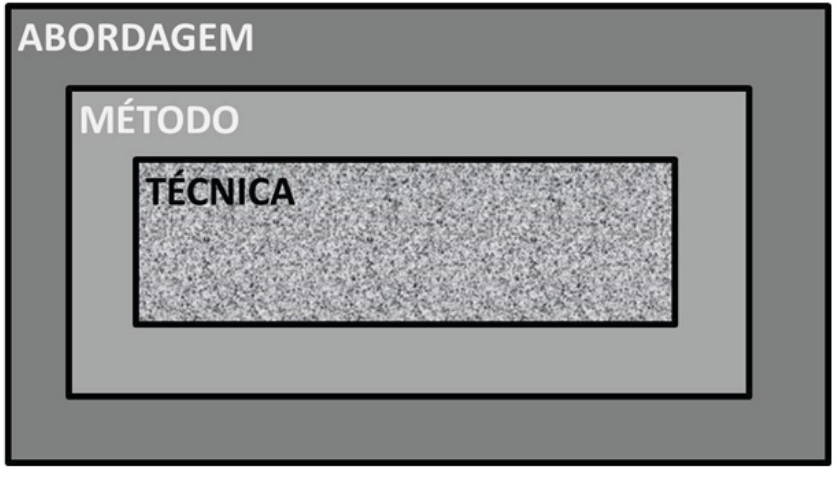

Fonte: autoria própria

A partir da representação proposta, consideramos que as técnicas selecionadas pelo(a) professor(a) são constituídas a partir das diretrizes de um método adotado por ele(a) e por sua instituição de ensino e tal

3. No original: techniques carry out a method which is consistent with an approach. 
método se origina das premissas de determinada abordagem de ensino, sendo que esta é determinada também pela abordagem de ensino do(a) professor(a).

Ainda na busca de melhor conceituar esses termos, Richards e Rodgers (1986), fazem uma revisão dos termos cunhados por Anthony (1963) e defendem que o termo mais amplo, ou "guarda-chuva", ao invés de abordagem, é método. $\mathrm{O}$ modelo proposto pelos autores encontra-se ilustrado na Figura 2.

Figura 2 - Componentes do Método

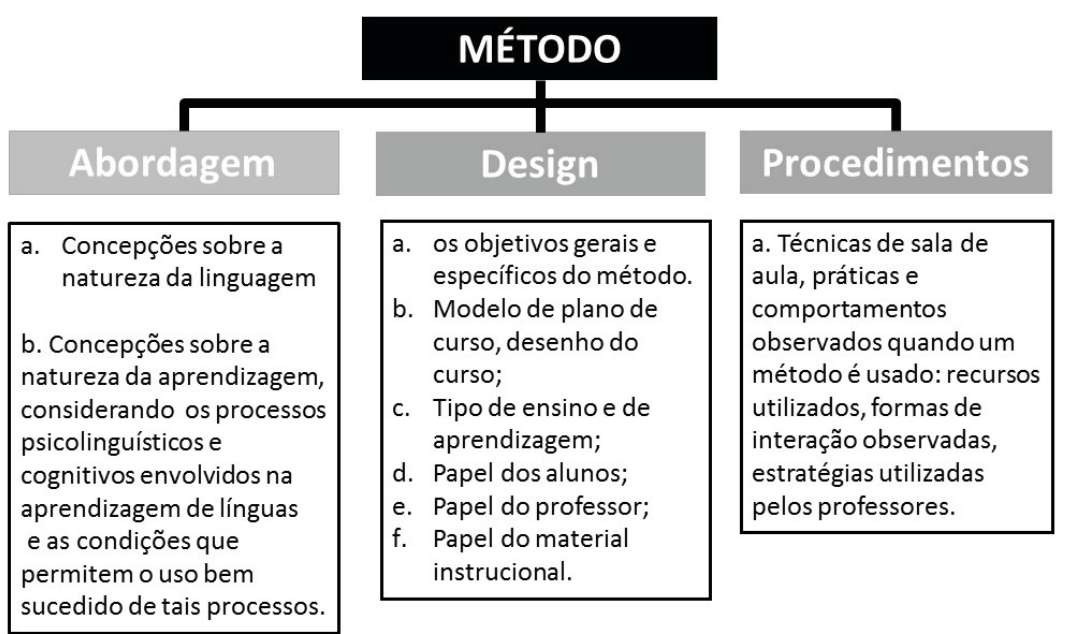

Fonte: baseado em Richards e Rodgers (1986, p. 28)

Nota-se que a definição de abordagem dos referidos autores está coerente com a proposta de Anthony (1986). No entanto, para Richards e Rodgers, é o método que tem sentido mais amplo, subdividindo-se em três grandes componentes (abordagem, design e procedimentos). Procedimentos, na teorização desses autores, corresponderia à noção de técnica, conforme proposto por Anthony (1963), Leffa (1988) e Almeida Filho (2012).

Os termos são importantes para compreendermos que o fazer dos professores constitui um conjunto de técnicas, mas que se encontram inseridas em determinado método e partem de premissas de uma aborda- 
gem, ou seja, de crenças sobre a linguagem, o papel do(a) professor(a), do aluno, e outros aspectos, conforme discutido anteriormente.

É no momento do planejamento que o(a) professor(a) deverá refletir sobre os elementos que fundamentarão sua aula e definir suas técnicas de ensino. Por tratar-se de momento tão decisivo, focalizaremos outros trabalhos sobre essa temática na seção seguinte.

\subsection{Planejamento de aulas: reflexões e propostas}

O planejamento de aulas tem sido foco de discussão, tanto em trabalhos científicos quanto em blogs de professores e documentos institucionais. Consenso entre os autores é o fato de que um planejamento adequado é imprescindível para uma aula bem sucedida e que, para sua elaboração, é necessário levar em consideração os inúmeros aspectos inerentes ao processo educacional.

Em trabalho mais informal e que circula entre professores, André Gazola $^{4}$ apresenta uma discussão sobre a elaboração de um plano de aula e afirma que a estrutura clássica de um planejamento consiste no estabelecimento ou seleção de: a) objetivos, b) tópicos do conhecimento; c) cronograma de trabalho; d) formas de mediação, e) recursos f) avaliação, e g) bibliografia.

Embora tais elementos, de fato, sejam fundamentais para se pensar um plano de aula, eles não dão ao(à) professor (a) as informações necessárias para seu agir em sala, uma vez que o contexto, as relações e as interações em sala de aula afetarão significativamente cada um dos elementos dessa estrutura.

A noção de "sequencia didática" (SD) também pode auxiliar o (a) professor(a) no planejamento de aulas. O conceito foi utilizado por Dolz, Noverraz e Schneuwly (2004) para o ensino-aprendizagem dos gêneros textuais (orais e escritos) e consiste em etapas de trabalho que vão da apresentação da situação à produção final. Tais etapas encontram-se representadas na Figura 3.

4. André Augusto Gazola é formado em Letras, professor de Literatura e História da Arte, pós-graduado em Metodologia de Ensino de Língua Portuguesa e Literatura e fundador do blog Lendo.org., acessível em https://www.lendo.org/como-fazer-um-plano-de-aula/ 
Figura 3 - Etapas de uma sequência didática

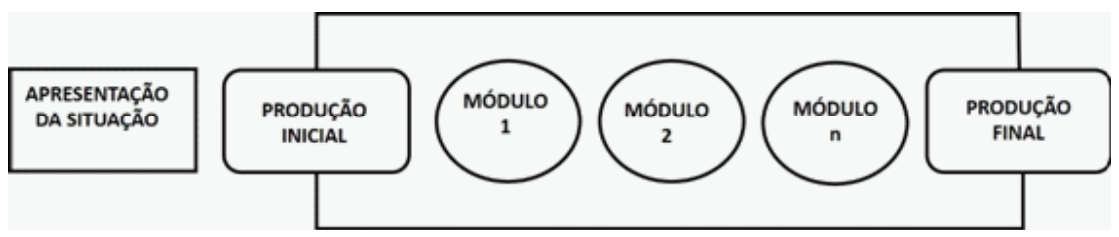

Fonte: DOLZ, NOVERRAZ E SCHEUWLY, 2004, p. 64

De acordo com os autores, a partir do trabalho sistemático proposto no modelo, é possível levar o aluno não apenas à compreensão dos diferentes gêneros textuais, mas também à produção. Ainda conforme os autores, o procedimento em módulos "se inscreve numa perspectiva construtivista, interacionista e social que supõe a realização de atividades intencionais, estruturadas e intensivas que devem adaptar-se às necessidades particulares dos diferentes grupos de aprendizes" (DOLZ; NOVERRAZ; SCHNEUWLY, 2004:93). Os módulos devem ser construídos progressivamente, visando levar os alunos a desenvolver os saberes necessários à elaboração do gênero em foco.

A noção de SD é relevante, pois, conforme os estudiosos, "procura favorecer a mudança e a promoção dos alunos ao domínio dos gêneros e das situações de comunicação" (idem, 2004: 97). Nesse sentido, ela nos auxilia a pensar também em uma sistematização da aula de língua estrangeira em perspectiva contemporânea, ou seja, aquela que tem o objetivo de preparar o aluno para a comunicação em diferentes situações de uso da língua-alvo.

Nesse campo específico do ensino e aprendizagem de línguas estrangeiras, alguns autores se dedicaram especificamente às reflexões sobre planejamento de cursos ou aulas. Almeida Filho (1993/2008; 2012) e Barbirato e Silva (2018) ocupam posição de destaque entre eles.

Almeida Filho (1993/2008; 2012) parte de uma definição de planejamento como

o processo ordenado e mapeado de decisões sobre inserções do conteúdo linguístico (amostras da língua-alvo, explicações, generalizações sobre aspectos sistematizáveis dessas amostras e automatizações eventuais), do tipo de processo que está engendrado no curso (interativo, negociador, criativo...), 
e sobre a língua-alvo, num curso apresentado em forma de unidades para guiar o ensino e aprendizagem. (Almeida Filho, 2012:13)

O autor se alinha com a percepção de planejamento como processo que envolve, além de reflexão sobre conteúdos linguísticos e sobre o processo de aprendizagem, também o tipo de abordagem do(a) professor (a) e dos alunos, formando, assim, uma complexa teia de elementos a ele(a) subjacentes. O estudioso faz ainda uma diferenciação entre planejamento linear e cíclico $\mathrm{O}$ primeiro refere-se àquele "que representa uma progressão de um item de aprendizagem para outro", cada um logicamente decorrendo do anterior.

Almeida Filho (2012) tece críticas a esse tipo de estrutura, tendo em vista que considera "impossível isolar segmentos linguísticos simples” (p.44), ou seja, não há uma forma de se encarcerar determinados aspectos gramaticais artificialmente em unidades específicas. Assim, o planejamento cíclico lhe parece mais adequado, tendo em vista que implica uma volta "a um conjunto inicial, pré-selecionado de unidades de curso, de maneira que se possa expandi-las cada vez que forem retomadas em ciclos posteriores" (p.45). Para o autor, esse tipo de planejamento pode ser modificado ou expandido "para acomodar novas unidades de ensino exigidas pelas necessidades e interesses do aluno". Concordamos com o autor, tendo em vista que os fenômenos linguísticos sempre retornam em diferentes situações de comunicação. Ademais, embora haja, comumente, uma apresentação de elementos linguísticos de forma linear, isso não significa que tais fenômenos tenham sido, de fato, aprendidos pelo aluno e o (a) professor (a) deve sempre planejar algumas "voltas" a conteúdos já estudados, em novas ocorrências na língua, favorecendo a recorrência da prática de uso e expansão linguística.

Barbirato e Silva (2018) reuniram diferentes trabalhos que enfocam o planejamento de cursos de LE de natureza e propósitos distintos: o planejamento de cursos de língua para propósitos específicos, para a Aprendizagem Integrada de Conteúdo e Língua (AICL), para provas específicas (CELPE-BRAS), para o contexto bilíngue, bem como o planejamento de um curso na modalidade virtual, são temas abordados na coletânea das autoras.

Todavia, notamos que há poucos trabalhos na área que contemplam o planejamento da unidade da aula de LE. Mais comumente há 
reflexões acerca de planejamento de cursos, entendidos, neste trabalho, como um conjunto de unidades de aula. Há de se considerar, porém, que o (a) professor (a), em especial aquele/aquela menos experiente, pode se sentir inseguro(a) ao planejar uma aula, diante de tantos elementos e aspectos a serem considerados nesse processo.

Nessa perspectiva, Almeida Filho (1993/2008), em seu significativo trabalho acerca do ensino comunicativo, apresentou uma reflexão sobre o planejamento de aulas e ilustra com figuras representativas, tanto o processo de constituição da aula quanto suas fases. De acordo com o autor, a aula tem como fundamento de constituição sua preparação, que por sua vez, advêm de: discussões com colegas, correção, avaliação de desempenho, produção de materiais, aperfeiçoamento profissional e seleção de livros didáticos (p.26). A partir de tal premissa, ele representa pictoricamente uma aula convencional como aquela que se constitui das fases: 1) clima e confiança; 2) apresentação de insumo novo; 3) ensaio e uso e 4) pano. (ibidem, 1993:29)

Em concordância com a natureza faseológica da aula, Rozenfeld e Viana (2006) também descreveram o planejamento de aula de línguas estrangeiras, analisando os elementos que a constituem e apresentando um modelo que visa facilitar ao (à) professor(a) o manejo de todos os aspectos inerentes à aula em uma prática coerente com o ensino contemporâneo. Após discutir os elementos presentes na aula (que serão abordados na próxima seção), os autores dividem suas fases em: 1) Introdução, 2) Preparação do insumo; 3) apresentação; 4) compreensão; 5) fixação; 6) transferência; 7) uso livre; 8) fechamento.

No entanto, muito embora o modelo possa auxiliar professores, defendemos que ele carece de revisão, de forma que se adeque melhor aos diferentes contextos e incorpore reflexões de estudos mais recentes da área. Com esse intento, apresentamos na seção a seguir uma proposta reconfigurada.

\section{Modelo de planejamento de aulas em fases}

Rozenfeld e Viana (2006) enfatizam que a aula constitui "espaço relevante no processo de ensino e aprendizagem de línguas" e que para que ela ocorra de maneira satisfatória é necessário que sejam 
considerados inúmeros aspectos pelo(a) professor(a). Tais aspectos são representados metaforicamente pelos autores por uma árvore, sendo que a raiz é composta pelos elementos que deverão ser considerados pelo(a) professor(a) ao planejar uma aula (e que darão os "nutrientes" para a copa), o tronco é o processo de planejamento, ou seja, o momento de reflexão do(a) professor(a) acerca de tais aspectos e de seleção de material, que levará, então, ao crescimento da copa da árvore (a aula), que, se bem "alimentada", poderá produzir bons frutos. A representação metafórica dos autores encontra-se na Figura 4.

Figura 4 - Representação metafórica de uma aula

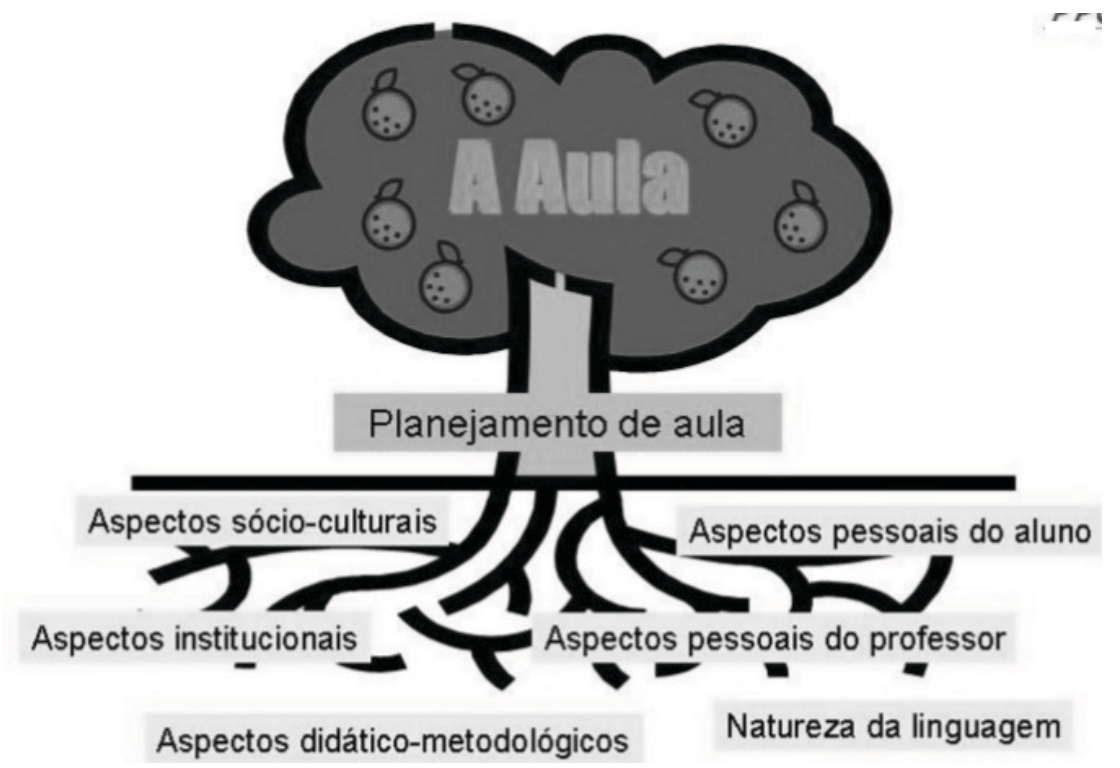

Fonte: Rozenfeld e Viana, 2006

Conforme Rozenfeld e Viana (2006), esses elementos que "alimentam" as aulas são descritos da seguinte forma:

a) aspectos socioculturais - referem-se ao contexto sociocultural no qual os alunos e professores estão inseridos, tais como política de ensino/ aprendizagem de LE, relação do contexto dado com a língua e cultura-alvo, ambiente linguístico etc.

b) aspectos institucionais - são aqueles que incluem, por exemplo, tempo disponível para se atingir objetivos pré-estabelecidos, material disponibili- 
zado na instituição, livro didático adotado, perfil dos alunos, espaço físico da escola e das salas de aula, recursos tecnológicos disponibilizados, número de alunos por sala etc. Os aspectos institucionais e socioculturais não são, na maioria das vezes, passíveis de mudanças. Eles devem ser analisados pelo professor e este deverá tecer reflexões durante o planejamento acerca da adaptação de seus objetivos pedagógicos às condições ali encontradas.

c) aspectos didático-metodológicos - são os aspectos de caráter pedagógico, tais como objetivos a serem atingidos, procedimentos metodológicos (...), concepções metodológicas em relação ao erro, ao papel do professor em sala de aula, à forma de elaboração de temas socioculturais da língua-alvo, livro didático etc.

d) natureza da linguagem - A linguagem não se restringe a sua dimensão sistêmica (conjunto de estruturas linguísticas); sua compreensão deve envolver também cultura, sociedade, contexto e ideologia. (...)

e) aspectos pessoais do professor - fatores como formação profissional do professor, sua conduta frente aos alunos, à língua e cultura-alvo, filtro afeti$v^{5}$, que envolve também motivação pessoal para seu trabalho, abordagem de ensino, personalidade etc.

f) aspectos pessoais do aluno - referem-se às características dos alunos como idade, conhecimento de outra LE, procedência, interesse, dificuldades, estilos de aprendizagem, atitude, conhecimento prévio, criatividade, filtro afetivo (por exemplo, motivação, empatia, grau de ansiedade etc), abordagem de aprender e outros.

Neste trabalho, mantemos a posição defendida anteriormente no que se refere ao papel fundamental do planejamento para o sucesso de uma aula e também no que se refere aos aspectos que a constituem. Ampliando a discussão dos autores, sustentamos que os aspectos institucionais e didático-metodológicos envolvem, na contemporaneidade, uma reflexão mais cuidadosa sobre a modalidade de ensino e também as mídias a serem utilizadas.

No passado, o livro didático e os áudios ocupavam papel central como recursos didáticos de sala de aula. Hodiernamente, as questões acerca da modalidade de ensino (presencial, a distância ou híbrida) e

5. O termo filtro afetivo (affective filter) foi utilizado primeiramente por Krashen (1982), como uma das hipóteses do Modelo Monitor de aquisição de segunda língua, em referência aos estado emocional e psicológico do aluno durante o processo de aprendizagem. Quanto mais baixo ele for, maior a motivação, o interesse, menor a ansiedade. O filtro afetivo alto, ao contrário, atua negativamente na aprendizagem, pois envolve sentimentos de forte ansiedade e pouca motivação e baixo interesse. 
dos tipos de recursos tecnológicos a serem utilizados devem ocupar também um papel importante no processo de planejamento, tendo em vista que o interesse dos alunos (ou seja, aspectos pessoais afetivos) está bastante voltado para o uso de Tecnologias Digitais de Informação e Comunicação (TDICs).

Ainda em relação aos aspectos didático-metodológicos, defendemos a urgência de se considerar na definição dos objetivos e procedimentos, a relevância de uma prática docente pautada na pedagogia dos multiletramentos (Rojo e Moura, 2012) e do letramento crítico.

A pedagogia dos Multiletramentos foi proposta pela primeira vez no manifesto do Grupo de Nova Londres (GNL), a partir da premissa de que o "letramento multimodal é fundamental para a nossa inserção em um mundo onde significados emergem de forma cada vez mais translocal, multicultural e híbrida" (COPE; KALANTZIS, 2000). Nessa perspectiva,

o Grupo de Nova Londres defende que a educação se volte para formação de designers de significados capazes de compreender, produzir e transformar significados linguísticos, visuais, de áudio, gestuais e espaciais no processo de desenhar novos futuros sociais no trabalho, na esfera pública e na comunidade. (OLIVEIRA E SZUNDY, 2014, s/p)

O grupo toma como princípio fundador do termo, então, a noção de "multiplicidade de linguagens que opera no processo de construção de significados na contemporaneidade". Assim, o termo multiletramentos

foi escolhido para descrever dois importantes argumentos que se colocam diante da ordem cultural, institucional e global emergente: a multiplicidade de canais de comunicação e mídia e a importância crescente da diversidade linguística e cultural (CAZDEN, COPE et al., 1996, p.63, apud OLIVEIRA E SZUNDY, 2014)

Nesse sentido, ao considerar os aspectos didático metodológicos e definir os objetivos e procedimentos, o(a) professor(a) deve, sob perspectiva dos multiletramentos, ponderar sobre o trato da diversidade cultural e linguística presente na sociedade contemporânea, bem como 
sobre a multiplicidade de canais de comunicação e mídias pelos quais circulam textos na atualidade.

Direcionando o foco para a noção dos diferentes letramentos, também o Letramento Crítico dos alunos deve ser incentivado. Ele se constituiria a partir de práticas de leitura e escrita que levam em consideração o contexto geral e questões políticas, sociais e ideológicas, visando, assim, o desenvolvimento da leitura crítica de textos multimodais e da criticidade diante de formas sociais de construção de sentidos. Alguns autores já apontaram para a relevância de uma prática de ensino de línguas pautada no Letramento Crítico, como, por exemplo, Rozenfeld (2016:148), que refletiu sobre "o potencial do ensino de alemão em escolas públicas brasileiras, não apenas para a aprendizagem de um novo idioma, mas também para uma formação crítica e cidadã dos alunos".

Ainda em relação aos aspectos didático-metodológicos, é necessário enfatizar, no que concerne a "Natureza da Linguagem", a indissociabilidade entre língua e cultura, tendo em vista que a língua como ato comunicativo, se constrói em um ambiente cultural específico. Conforme Salomão (2015:383):

A cultura no ensino de línguas foi geralmente colocada como um conjunto de conhecimentos sobre os produtos, práticas e perspectivas de um povo, associado a um estado-nação que "detém" determinada língua e sua respectiva cultura. Ao entendermos tais concepções como essencialistas, que desconsideram o caráter interacional, assim como a variabilidade, dinamicidade e complexidade da cultura, entendemos que a formação de professores carece de reflexão sobre o modo de se inserir criticamente e mais concretamente a discussão sobre o componente cultural. Há que se ir além da concepção aparentemente generalizada de conhecimentos sobre o outro que devem ser transmitidos, comparados com o próprio país, copiados ou incorporados como uma quinta habilidade, uma vez que se mostra factoide e estática ao tratar o componente cultural como um bloco monolítico, transparente, isento de conflitos e independente de interpretações, que deve ser aceito de forma dogmática pelo aprendiz ou usado como uma ferramenta de comunicação (da qual se pode lançar mão para resolução de problemas, não influenciando a (re)construção de sua identidade). 
A autora chama a atenção para as mudanças que ocorreram nas últimas décadas em relação ao trato de aspectos culturais em sala de aula. A mera apresentação de produtos, fatos, e hábitos de um povo não abrange a complexidade e a dinamicidade do conceito de cultura, podendo levar à formação de estereótipos, que são prejudiciais para o processo de aprendizagem. A reflexão acerca de elementos culturais de maneira crítica, bem como a forma de tratar tais questões em sala de aula, é também um dos elementos de grande importância no âmbito dos aspectos didático metodológicos. Há de se considerar ainda, que na sociedade atual, em que barreiras de tempo e espaço são flexibilizadas pelo advento da internet, é importante que os alunos tenham o conhecimento das culturas dos países da língua-alvo, para que possam melhor compreender a alteridade e as situações de comunicação em outros espaços.

Em outras palavras, para um planejamento adequado, o(a) professor(a) deve se pautar, não apenas em orientações de documentos oficiais e em conteúdos preestabelecidos em livros didáticos, mas avaliar as noções de língua e cultura que subjazem tais orientações e conteúdos. Ademais, é necessário refletir acerca de questões inerentes a seu contexto específico, como a motivação dos alunos, o grau de interesse, os recursos disponíveis na escola, a possibilidade de uso da internet em sala e fora dela, a natureza dialógica da linguagem e premissas teóricas do campo do ensino e aprendizagem de línguas, entre outros inúmeros fatores.

Assim, a fim de melhor sistematizar todas as reflexões necessárias, propomos um planejamento criterioso e uma organização fásica dessa unidade do processo e do espaço de ensinar e aprender. A representação de tal planejamento se encontra na Figura 5. 
Figura 5 - Representação da aula de línguas estrangeiras
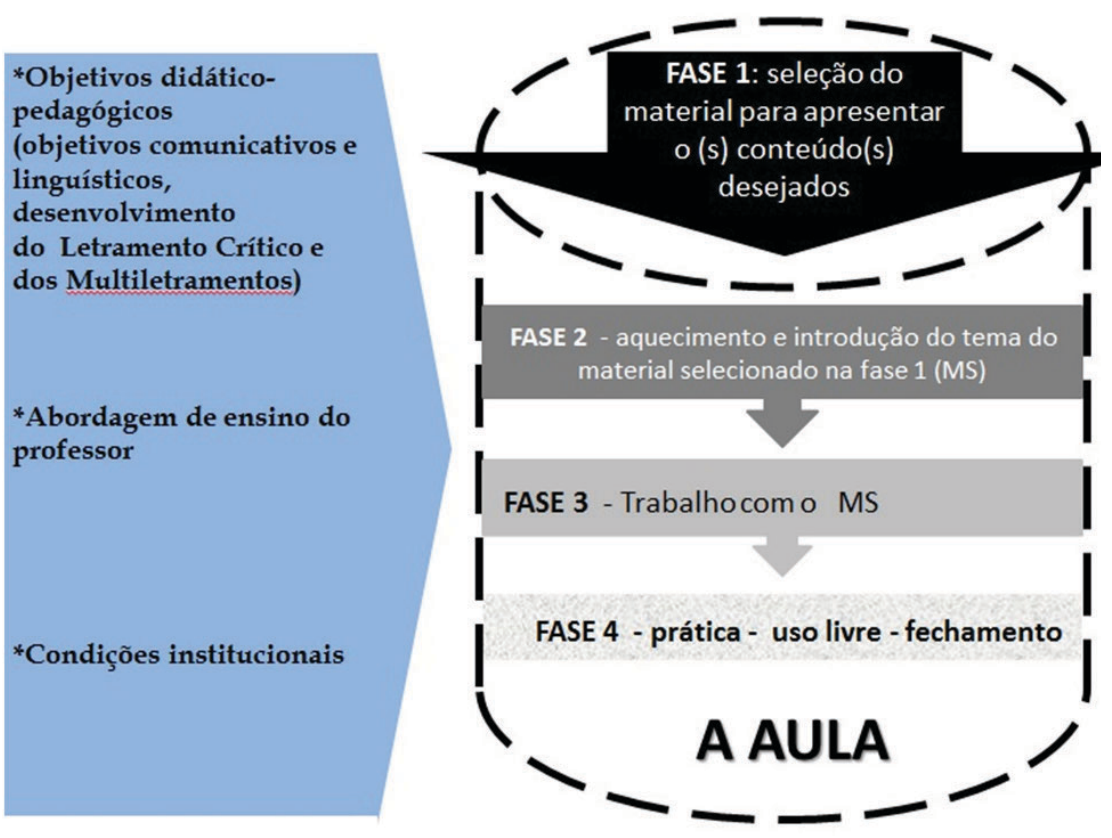

Fonte: autoria própria

Na figura 5 apresentamos uma proposta de representação da aula, desde os elementos que influenciarão sua constituição até o seu encerramento. Iniciando pelos elementos situados à esquerda da imagem, e em relação aos objetivos didáticos-metodológicos, é importante que o(a) professor(a) parta de uma abordagem contemporânea de ensino de línguas (abordagem comunicativa, intercultural, pedagogia pós-método ${ }^{6}$ ), que envolve o trato de aspectos culturais, a percepção do aluno como agente do processo de aprendizagem, a língua como dinâmica e negociável em situações de comunicação. Aliado a esse aspecto, o(a) professor(a) deverá se pautar, ainda, nas condições institucionais sob as quais ele trabalha: no projeto político pedagógico, no tempo de aula, nos recursos disponíveis, no número de alunos e outros. Conforme discutido por Rozenfeld e Viana (2006), consideramos que o livro didático pode ocupar um papel importante na aula, mas que ele não deve ser seguido fielmente e ser o único elemento a guiar as

6. Não nos deteremos na descrição de cada uma dessas perspectivas uma vez que elas se encontram amplamente discutidas na literatura da área. (cf. p. ex. Vieira-Abrahão, 2015) 
ações do(a) professor(a). Para análise do material a ser utilizado (livros didáticos e/ou outros à escolha do/a professor/a), é de suma importância que o(a) professor(a) utilize o terceiro elemento que fundamenta seu fazer, ou seja, a reflexão. A postura crítico-reflexiva do/a professor/a (SCHÖN, 1983) lhe permitirá lançar um olhar questionador sobre o livro, (eventualmente, prescrito pela instituição de ensino), de forma que ele possa adaptá-lo ao seu contexto e aos seus objetivos. Rozenfeld (2014), ao discutir a prática reflexiva, apoiada em Schön, sustenta que esse procedimento é aquele que

ajudará profissionais a adquirir os tipos de arte essenciais para as competências em zonas indeterminadas de prática, se referindo ao termo "arte profissional" (Professional Artistry) como conjunto de competências que os profissionais possuem em situações únicas, incertas e conflituosas da prática. (ibidem, 2011, p.25)

A "arte profissional", de acordo com Schön (1987, apud ROZENFELD, 2011, p.25) consiste no conjunto de competências que

se relacionam aos princípios do "conhecimento-em-ação" e "reflexão-emação" (op.cit. 1987, p.22-40). O conhecimento em ação é o conhecimento tácito, implícito, interiorizado que se encontra na ação. No entanto, ele não é suficiente, e por meio da reflexão em ação o profissional poderá tentar compreender o conhecimento que está implícito durante a ação e este processo poderá influenciar próximas ações, criando novos caminhos, novas soluções e criando assim um repertório de experiências que poderá ser mobilizado em situações similares futuras. Esse processo de reflexão-em-ação é central para a forma pela qual profissionais lidam com situações de instabilidade, de singularidade e de conflito de valor (SCHÖN, 1983, p. 49-50). As novas situações demandarão, por sua vez, novas análises, novas contextualizações, possíveis explicações, uma apropriação de teorias sobre o problema, uma investigação. A esse processo o autor denomina "reflexão sobre ação". De acordo com ele, refletimos sobre ação, pensando sobre ações passadas, sobre o que fizemos, a fim de descobrir como nosso conhecimento em ação pode ter contribuído para um resultado inesperado. (SCHÖN, 1983, apud ROZENFELD, 2011, p.25)

Em outras palavras, partindo da abordagem de ensino do(a) professor(a), de suas condições de ensino e da reflexão sobre o conhecimento-em-ação e reflexão-na-ação (reflexões sobre outras aulas), ele 
deverá definir os seus objetivos didático-pedagógicos e procedimentos de ensino.

De maneira geral, consideramos que todo processo de constituição da aula, desde seu planejamento até o fechamento, deve ser permeado pelo incentivo ao desenvolvimento do Letramento Crítico e dos Multiletramentos dos alunos, conforme discutido anteriormente. Na figura 5, o invólucro da aula é representado de forma pontilhada, simbolizando seu caráter permeável e o fato de que os elementos dispostos à esquerda influenciarão todo o processo, de seu início ao final, não se restringindo a uma fase específica.

Considerando a parte direita da figura, ou o que representa a aula na figura 5, o(a) professor(a) deverá, na Fase 1, selecionar o conteúdo e o material a serem apresentados aos alunos. O material pode ser, por exemplo, um texto, um vídeo, um áudio, diálogo, de acordo com as habilidades que deseja desenvolver, seus objetivos linguísticos e comunicativos e o quadro contextual que subjaz a sua aula (perfil dos alunos, tempo de aula, relação do conteúdo com aulas anteriores, prescrições curriculares, condições institucionais). É importante que o(a) professor(a), nessa fase, avalie cuidadosamente o conteúdo a ser apresentado, prevendo, também, possíveis dificuldades a serem encontradas pelos alunos. Tais dificuldades poderão ser minimizadas a partir de uma boa preparação do insumo na fase 2 , como veremos adiante.

A Fase 2 (Aquecimento e introdução do tema selecionado), que ocorre em sala de aula, inicia-se com o trabalho junto aos alunos em diferentes etapas:

a) discussão de questões organizacionais: entrega de tarefas, notas, avisos gerais, por exemplo. Conforme Rozenfeld e Viana (2006), "nessa fase é feita uma iniciação ao trabalho global da aula" e "a transmissão de informações de cunho organizacionais, institucionais ou pedagógicos".

b) aquecimento: construção de um clima de confiança para inserção dos alunos em um ambiente de trabalho harmonioso. É o momento de retomar conteúdos vistos anteriormente (por exemplo, o vocabulário ou temáticas específicas) para, paulatinamente, deslocar a atenção dos alunos para o espaço da sala de aula. Nesse momento pode-se utilizar 
um jogo breve, ou uma conversa, visando a recapitulação de conteúdos anteriores. Por tratar-se, porém, de uma fase de aquecimento, deve-se atentar para não se despender muito tempo da aula nessa etapa. Conforme Rozenfeld e Viana (2006), esse é um momento "fundamental para trazer o aluno para o espaço da aula que se inicia e para despertarlhe o interesse e a motivação", e que, portanto, "tem papel de grande relevância na aula e nas fases posteriores".

c) preparação do insumo: a terceira e última atividade dessa fase é destinada a preparar o insumo, a temática e o material que foi selecionado na fase 1 pelo(a) professor(a). O objetivo dela é introduzir e preparar o insumo a ser apresentado na fase seguinte, na Apresentação. Partindo da noção freiriana de que um aluno não é uma "tábula rasa", mas que traz para a sala de aula diferentes conhecimentos de mundo, busca-se, também, nesse momento, fazer um levantamento de seu conhecimento prévio sobre o assunto. Assim, esse momento é voltado para: 1) fazer um levantamento do conhecimento prévio do aluno sobre o tema e de seu interesse sobre a temática a ser proposta na fase subsequente, 2) despertar sua curiosidade e 3 ) introduzir conteúdo lexical a ser trabalhado posteriormente, visando facilitar sua compreensão no momento de confronto com o material (promoção do sentimento "Aha-Gefühl", a ser discutido na fase seguinte).

A fase 2 que propomos (etapas a, b e c) está em consonância com a primeira fase (Clima e confiança) proposta por Almeida Filho (1993/2008, p.29-30), a qual deve ser destinada ao estabelecimento de clima de confiança e de atmosfera de "estrangeiridade e expectativa sobre o que vai ser propiciado como oportunidades de aprendizagem da língua-alvo" e será fundamental para promover o baixo filtro afetivo do aprendiz, motivando, despertando interesse, reduzindo a ansiedade, valorizando seu conhecimento prévio.

Na sequência, o(a) professor(a) passa para a Fase 3. É importante que se tome o cuidado de não gerar rupturas abruptas entre as fases. Ao contrário, deve-se ir criando pontes entre elas, ou seja, estabelecer

7. Gefühl, em português significa sentimento. Aha-Gefühl pode ser traduzido, portanto, como "sentimento "ahhh....é isso" ou "ahh...entendi", utilizado coloquialmente quando se compreende alguma coisa. O Aha-Gefühl foi explicado, por exemplo, em REHBEIN, 1997, p.173) como a alegria que, geralmente, acompanha um reconhecimento (No original: Die Freude, die man als Aha-Gefühl bezeichnet, begleitet im allgemeinen eine Erkenntnis.) 
conexões entre as fases 2 e 3 , bem como posteriormente entre a 3 e a 4. A fase 3 é o momento de o(a) professor(a) apresentar o material selecionado na fase 1 e que será central para se atingir os objetivos pedagógicos estabelecidos. Assim, é o momento de encontro do aluno com um texto escrito ou multimodal na língua-alvo. Tendo o insumo sido bem preparado na fase anterior, ocorrerá no aluno o "Aha-Gefühl", que, conforme mencionamos, se refere à alegria de reconhecimento linguístico e entendimento, ou seja, refere-se ao sentimento de compreensão despertado no aprendiz. Esse sentimento atua positivamente no filtro afetivo do aluno, na sua autoimagem, aumentando sua motivação, a confiança em si e o interesse na aprendizagem.

Chamamos essa fase de "Trabalho com o MS", pois trata-se do momento em que serão realizadas atividades com o insumo selecionado na fase 1. Nessa etapa, busca-se levar o aluno à compreensão do conteúdo, por meio de questões norteadoras (de forma escrita, oral, na lousa, no Datashow, ou da forma avaliada como mais adequada) e pela introdução de novos itens lexicais. $\mathrm{O}(\mathrm{a})$ professor(a) irá destacar o conhecido, elucidar o desconhecido, apontar o que é central para seu objetivo, bem como o que não deve ser considerado naquele momento. Esse trabalho deve ser cuidadosamente planejado antes da aula e realizado por meio de atividades específicas para isso, a serem desenvolvidas em duplas, individualmente, de forma expositiva ou em grupo, a depender do objetivo do professor em relação à dinâmica.

Para finalizar, na Fase 4 (Prática - uso livre - fechamento) o objetivo central é o uso da língua-alvo em situações significativas de comunicação. Se necessário, antes de passar ao uso livre (que pode ocorrer por meio da discussão do tema apresentado na fase anterior, de um role play de forma livre sobre a situação apresentada, de reflexão sobre aspectos da cultura-alvo em contraposição à própria, a depender da temática abordada e dos objetivos do/a professor/a), os alunos poderão se preparar linguisticamente para tal uso a partir da realização de exercícios de sistematização dirigidos e/ou de repetição (denominado por nós nessa fase como Prática). A repetição, criticada por alguns autores por se apresentar em abordagens anteriores com caráter mecânico e descontextualizado (cf. p. ex. Vieira Abrahão, 2015), pode ser de grande valia, quando inserida em uma sequência 
bem planejada, contextualizada e como preparo para a comunicação significativa. Para que esse uso livre aconteça,

o professor deverá propor, com base em suposições sobre o que possa ser uma situação de interesse e próxima da realidade de seus alunos, situações em que eles tenham a possibilidade de se comunicar livremente utilizando o novo insumo em contexto significativo. (Rozenfeld e Viana, 2006)

Ainda nessa fase, propomos o fechamento, momento em que o(a) professor(a) finalizará as atividades da aula, promoverá apreciação do trabalho desenvolvido e proporá trabalho autônomo, por meio da sugestão, por exemplo, de aplicativos, sites, filmes, exercícios do livro ou pesquisas na internet.

\section{Considerações Finais}

Embora o planejamento e a aula de línguas possam parecer algo simples, ambos envolvem a consideração de diferentes aspectos e um minucioso processo de reflexão. Por essa razão, buscamos, neste trabalho, discutir os componentes que constituem a aula e também propor uma representação das suas fases, que permite ao (à) professor (a) organizar os conteúdos e incorporar, na unidade de aula, importantes premissas didático-metodológicas que subjazem à prática de forma adequada e relevante para o aluno contemporâneo. Para tanto, discutimos diferentes conceitos do campo da Linguística Aplicada que fundamentam uma aula, como a noção de Abordagem de Ensino, de Multiletramentos, de Letramento Crítico e Professor Crítico Reflexivo. Com base nos pressupostos teóricos, tendo em vista as condições institucionais e os objetivos didático-pedagógicos, propomos que a aula de língua estrangeira seja organizada em, ao menos, quatro fases, a saber: seleção do material (fase 1), aquecimento e introdução (fase 2), trabalho com o MS (fase 3) e prática-uso livre-fechamento (fase 4). A fase 1 ocorre previamente à aula e envolve apenas o(a) professor, enquanto as fases 2, 3 e 4 acontecem na instituição de ensino junto aos alunos. A fase 2 tem o intuito de dar início aos trabalhos com os alunos e de introduzir a eles a temática do material selecionado na fase 1. Já a fase 3 é destinada à apresentação do insumo por meio de material 
selecionado na fase 1 e a 4 à prática e ao uso livre da língua. Ao final dessa fase, ocorre o fechamento da aula.

Esperamos, com este trabalho, contribuir para a prática do(a) professor(a) de línguas e para pesquisas da área de ensino e aprendizagem de línguas estrangeiras, bem auxiliar em programas de formação inicial e continuada de professores.

\section{Referências bibliográficas}

ALMEIDA FILHO, José Carlos Paes de. 1993/2008. Dimensões comunicativas no ensino de linguas. Campinas: Editora Pontes. $75 \mathrm{p}$.

ALMEIDA FILHO, José Carlos Paes de. 2012. Quatro estações no ensino de línguas. Campinas: Editora Pontes. 130p.

ANTHONY, Edward M. 1963. Approach, method and technique. English language teaching, ELT Journal, Vol. 17, $\mathrm{Nr} 2$, 1963, p. 63-67. Disponível em https://doi.org/10.1093/elt/XVII.2.63. Acesso em 23/01/2019.

BARBIRATO, Rita de Cássia e SILVA, Vera Lúcia Teixeira da. 2018. Planejamento de cursos de línguas: traçando rotas, explorando caminhos. Campinas: Editora Pontes, 2018. 206p.

CANDAU, Vera Maria (Org.) 2013. A didática em questão. Petrópolis: Editora Vozes. 128p.

CAZDEN, Courtney; COPE, Bill; FAIRCLOUGH, Norman; GEE, James Paul; et al. 1996. A Pedagogy of Multiliteracies: Designing Social Futures. Harvard Educational Review; n. 66.1. p. 60-92.

COPE, Bill; KALANTZIS, Mary (ed.). 2000. Multiliteracies: Literacy Learning and the Design of Social Futures. Routledge: Psychology Press. 350p.

DOLZ, Joaquim; NOVERRAZ, Michele; SCHNEUWLY, Bernard. 2004. Sequências didáticas para o oral e a escrita: apresentação de um procedimento. In: SCHNEUWLY, Bernard; DOLZ, Joaquim. Gêneros Orais e escritos na escola. Trad. e org. ROJO, Roxane H. Rodrigues; CORDEIRO, Glaís Sales. São Paulo: Mercado das Letras, p. 95-128. GRUPO DE NOVA LONDRES. 2000. A Pedagogy of Multiliteracies: Designing Social Futures. In: COPE, Bill.; KALANTZIS, Mary. (Ed.). Multiliteracies: literacy learning and the design of social futures. Routledge: Psychology Press, p. 9-37. 
KRASHEN, Stephen. 1982. Principles and practice in second language acquisition. Oxford: Pergamon. Disponível em: http://www. sdkrashen.com/content/books/principles_and_practice.pdf. Acesso em 21 de janeiro de 2019.

LARSEN-FREEMAN, Diane e ANDERSON, Marti. 2011. Techniques \& Principles in Language teaching. Oxford University Press. 272p.

LEFFA, Vilson. 1988. Metodologia do ensino de línguas. In: BOHN, H. I.; VANDRESEN, P. Tópicos em lingüística aplicada: O ensino de línguas estrangeiras. Florianópolis: Ed. da UFSC. p. 211-236.

SALOMAO, Ana Cristina Biondo. 2015. O componente cultural no ensino e aprendizagem de línguas: desenvolvimento histórico e perspectivas na contemporaneidade. Trabalhos em Linguística Aplicada, vol. 54, n. 2, p. 361-392.

SCHÖN, Donald. 1987. Educating the Reflective Practioner. San Francisco, Jossey-Bass Publishers.

OLIVEIRA, Maria Bernardete Fernandes; SZUNDY, Paula Tatiane C. 2014. Práticas de multiletramentos na escola: por uma educação responsiva à contemporaneidade. Bakhtiniana: Revista de Estudos do Discurso, vol. 9, n. 2, São Paulo. Disponível em: http://www.scielo. br/scielo.php?script=sci_arttext\&pid=S2176-45732014000200012. Acesso em: 23/01/2019.

REHBEIN, Boike. 1997. Was heisst es, einen anderen Menschen zu verstehen? Stuttgart: M \& P-Verlag für Wissenschaft und Forschung. $228 \mathrm{p}$.

RICHARDS, Jack C. e RODGERS, Theodore S. 1986. Approaches and Methods in Language Teaching. Second Edition. Cambridge: Cambridge University Press. 271p.

ROJO, Roxane e MOURA, Eduardo. 2012. Multiletramentos na escola. São Paulo: Parábola. 264p.

ROZENFELD, Cibele Cecilio de Faria e VIANA, Nelson. 2006. Planejamento de aula: uma reflexão sobre o papel do livro didático e as fases da aula. Anais do II Congresso ABRAPA, 2006. Disponível em: http://www.abrapa.org.br/cd/npdfs/Rotzenfeld-Viana.pdf. Acesso em 3/07/2019.

ROZENFELD, Cibele Cecilio de Faria. Fóruns online na formação críticoreflexiva de professores de línguas estrangeiras: uma representação do pensamento crítico em fases na/pela linguagem. Alfa, rev. linguíst. (São José Rio Preto) [online]. 2014, vol.58, n.1, pp.35-62. ISSN 19815794. http://dx.doi.org/10.1590/S1981-57942014000100002. 
ROZENFELD, Cibele Cecilio de Faria. (2016). O ensino de alemão em escolas públicas pela perspectiva do letramento crítico: um subprojeto PIBID em foco. Pandaemonium Germanicum, 19(27), 148-174. https://doi.org/10.11606/1982-88371927148174.

SCHÖN, Donald. 1983. The Reflective Practioner: how professionals think in action. Basic Books. 374p.

SCHÖN, Donald 1987. Educating the Reflective Practioner. San Francisco, Jossey-Bass Publishers. 376p.

VIEIRA-ABRAHÃO, Maria Helena. 2015. Algumas reflexões sobre a abordagem comunicativa, o pós-método e a prática docente. Revista EntreLinguas, Araraquara, v.1, n.1. p. 25-41.

VILAÇA, Marcio Luiz Corrêa. 2008. Métodos de Ensino de Línguas Estrangeiras: fundamentos, críticas e ecletismo. Revista Eletrônica do Instituto de Humanidades, vol. VII, n. 26. Disponível em: http://publicacoes.unigranrio.edu.br/index.php/reihm/article/ viewFile/43/78. Acesso em 15 de janeiro de 2019.

Recebido em: 03/02/2019

Aprovado em: 13/09/2019 